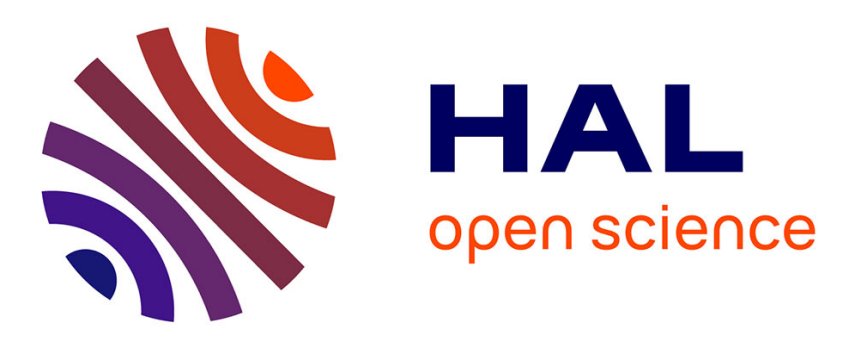

\title{
Sustainable Synthesis of Hierarchical MWW Zeolites Using Silica from an Agro-industrial Waste, Rice Husk Ash
}

\author{
Jaíne Fernanes Gomes, Alexander Sachse, José Ribeiro Gregório, Katia \\ Bernardo-Gusmão, Anderson Joel Schwanke
}

\section{To cite this version:}

Jaíne Fernanes Gomes, Alexander Sachse, José Ribeiro Gregório, Katia Bernardo-Gusmão, Anderson Joel Schwanke. Sustainable Synthesis of Hierarchical MWW Zeolites Using Silica from an Agroindustrial Waste, Rice Husk Ash. Crystal Growth \& Design, 2019, 10.1021/acs.cgd.9b00974 . hal02352195

\section{HAL Id: hal-02352195 \\ https://hal.science/hal-02352195}

Submitted on 6 Nov 2019

HAL is a multi-disciplinary open access archive for the deposit and dissemination of scientific research documents, whether they are published or not. The documents may come from teaching and research institutions in France or abroad, or from public or private research centers.
L'archive ouverte pluridisciplinaire HAL, est destinée au dépôt et à la diffusion de documents scientifiques de niveau recherche, publiés ou non, émanant des établissements d'enseignement et de recherche français ou étrangers, des laboratoires publics ou privés. 


\section{Sustainable Synthesis of Hierarchical MWW Zeolites Using Silica from an Agro-industrial Waste, Rice Husk Ash}

Jaíne F. Gomes, ${ }^{\dagger}$ Alexander Sachse, ${ }^{\ddagger}$ José R. Gregório, ${ }^{\dagger}$ Katia Bernardo-Gusmão, ${ }^{\dagger}$ Anderson J. Schwanke*†

†Universidade Federal do Rio Grande do Sul, Departamento de Química Inorgânica, Av. Bento Gonçalves, 9500 Instituto de Química, Porto Alegre, Rio Grande do Sul, 91501-97o, Brasil

${ }^{\ddagger}$ Institut de Chimie des Milieux et Materiaux de Poitiers UFR SFA, Bât. B27, 4 rue Michel Brunet, TSA 51106 Poitiers, 86073, France.

*Corresponding author: anderson-js@live.com (A. J. S); Tel.: + 55 (51)3308-6302

KEYWORDS: sustainable zeolite synthesis, rice husk ash, MWW, MCM-22, hierarchical zeolites, pillaring, desilication

ABSTRACT: Sustainable and cost-efficient approach to obtain hierarchical MWW-type zeolites was developed through the use of silica extracted from rice husk ash; which is the largest agro-industrial waste product in the word. The effect of the concentration of $\mathrm{OH}^{-}$ions was determined in the synthesis of MWW-type zeolites with various chemical compositions. In addition, procedures to achieve hierarchical pillared and desilicated materials were assessed in order to obtain nano-architectures featuring intercrystalline or intracrystalline mesoporores. Nature and strength of acidity of materials was investigated through pyridine chemisorptions followed by IR. The impact of texture and acidity was evaluated on the acetalization reactions to produce bulky products.

\section{INTRODUCTION}

Zeolites are microporous crystalline solids composed of tetrahedral $\mathrm{TO}_{4}(\mathrm{~T}=\mathrm{Si}, \mathrm{Al})$ units coordinated by oxygen atoms. ${ }^{1}$ These aluminosilicates are a particular important materials class, which versatility is due to the spatial distribution of tetrahedral units that generate porous structures with an impressive variety of cavities and channels, featuring dimensions up to $2 \mathrm{~nm} .^{2}$ Moreover, the structural nature allows for tuning physicochemical properties, such as chemical composition, morphology, hydrophobicity and hydrophilicity. This explains their widespread application in numerous domains including catalysis, gas separa- tion and purification, cation exchange, environmental remediation, food industry, cosmetics, medicine, magnetism and microelectronics and development of green processes. ${ }^{3,4}$

Among the existing 245 zeolite structures, zeolites featuring MWW frameworks have received considerable attention as they belong to the rare examples of zeolites presenting a two dimensional lamellar zeolitic precursor (LZP)..$^{5}$ Indeed, the LZP MCM$22 \mathrm{P}$ and its tridimensional form (i.e. MCM-22) are the most famous and studied example of material with MWW topology, which further allow great versatility for the development of different hierarchical lamellar architectures and morphologies, such as organic-inorganic hybrids (MWW-BTEB- $\left.\mathrm{NH}_{2}\right)^{6}$, disordered 
assemblies $(\mathrm{MCM}-56)^{7}$, delaminated sheets $(\mathrm{ITQ}-2)^{8}$, nanosized MCM-22 ${ }^{9}$, pillared assemblies (MCM-36) $)^{10}$ and desilicated materials (MCM-22 and MCM-49). ${ }^{11}$ The unique structure of MCM-22 featuring 10 membered rings (MRs) and 12 MRs, empowers it with unparalleled catalytic activities, selectivities and stabilities for a variety of processes, such as in cracking, isomerizations, alkylations, hydroisomerizations, dehydration and aromatization. ${ }^{12}$ MCM-22 is indeed industrially exploited as catalyst in the Mobil/Badger cumene process. ${ }^{13}$ Moreover, zeolites featuring lamellar structure are extremely promising catalysts for the fine chemical production and for future biorefineries. ${ }^{14}$

One of the major drawbacks of zeolite synthesis is the cost of reactants that are required for their preparation. Indeed, the employed silica sources require several stages of extraction and purification; associated with important waste production. Expensive silica sources which are considered environmentally hazardous include fumed silica, colloidal silica, silicic acid and silicon alkoxides. ${ }^{15}$ It was reported that the use of such reactants arise to $40 \%$ of the total cost of the synthesis of industrially employed zeolites. ${ }^{16}$ The use of low-cost and environmental friendly silica sources e.g. clays minerals (smectite, sepiolite, kaolin, palygorskite, attapulgite, vermiculite, etc), diatoms, electronic waste, fly coal ash and silica from rice husk seems thus very promising, ${ }^{17}$

According to the latest FAO (Food and Agriculture Organization, ONU) report, the world paddy rice production in 2018 was 759.6 million tons. ${ }^{18}$ Approximately $20 \%$ of this value in weight corresponds to the rice husk $(\mathrm{RH})$, which is considered the worldwide biggest agro-industrial waste product. $\mathrm{RH}$ is often discarded or used as fuel in the proper rice mill industry or thermoelectric plants to produce heat or power as its composition contains $80 \%$ of organic material (lignocellulosic components). ${ }^{19}$ Even, the residue from combustion (approximately 20 $w t \%)$ of $\mathrm{RH}$ represents a non-valorized waste commonly named rice-husk ash (RHA), which up to date presents scarce commercial interest. Moreover, RHA needs to be discarded in proper waste disposal sites as its disposal in open fields would lead to severe environment risks related with water contamination, land and air pollution. RHA consists of $65-97 \%$ of amorphous silica, the rest being metallic oxides. Nowadays, considerable efforts are made in the quest to use the RHA silica for the production of added value materials, such as functional nanomaterials for energy and environment issues. ${ }^{20}$

As far as the MWW zeolite is concerned merely few studies report synthesis attempts through green strategies, which main focus is the replacement and recycling of the organic structure directing agent ${ }^{21}$ or of swelling agents to obtain swollen precursors. ${ }^{22}$ To the best of our knowledge, no reports have up to date been described on the development of synthetic strategies of hierarchical MWW materials through the use of sustainable silica sources. In the present communication we explore the possibility of using silica waste from rice husk with the aim to develop an environmentally friendly and at the same time low-cost rout to this highly promising zeolite materials.

\section{EXPERIMENTAL SECTION}

\section{Materials}

The RHA were kindly provided by SLC, a rice mill industry located in the state of Rio Grande do Sul, Brazil. All reactants used in the present study were purchased from Sigma-Aldrich with exception of $\mathrm{NaOH}$ (Nuclear).

\section{Calcination of RHA}

All experimental procedures for the preparation of silica sources and the synthesized materials were summarized in Scheme 1.

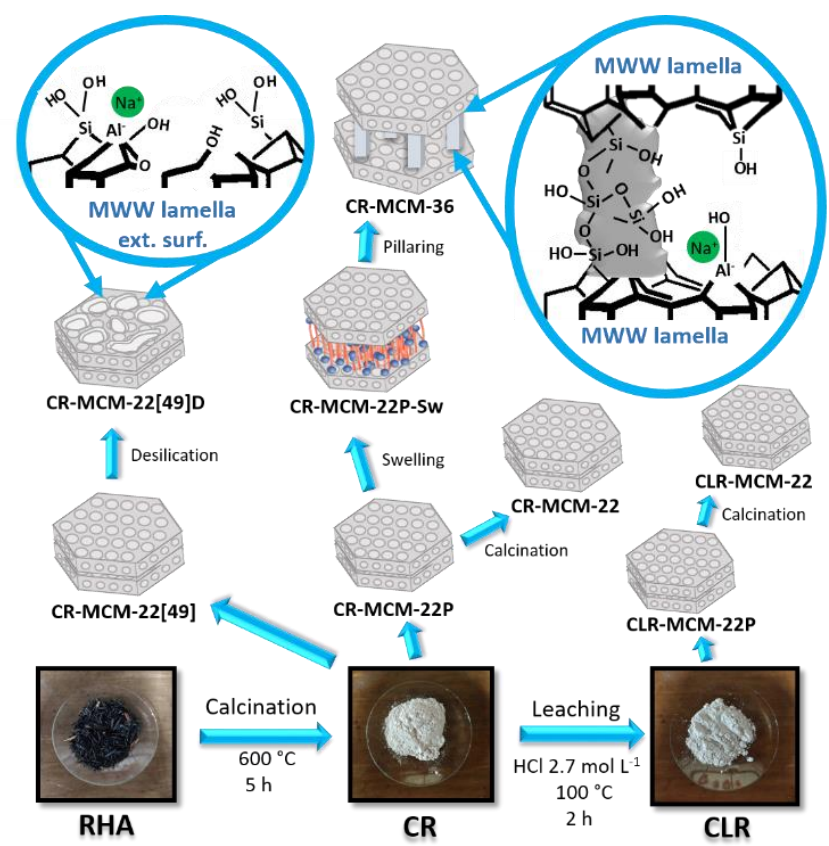

Scheme 1. General scheme of preparation of calcined rice husk ash (CR) and leached $C R$ (LCR) from rice husk ash (RHA) and their derivative MWW-type materials. 
The RHA was mechanically macerated into a fine powder and calcined at $600{ }^{\circ} \mathrm{C}$ for $5 \mathrm{~h}$ with a muffle furnace to remove organic residues. The obtained silica material was named CR ( Calcined Rice Husk Ash).

\section{Leaching of CR}

The leaching procedure was carried out using a mixture of 10 $\mathrm{g}$ of $\mathrm{CR}$ and $225 \mathrm{~mL}$ of $\mathrm{HCl}$ aqueous solution $\left(2.7 \mathrm{~mol} \mathrm{~L}^{-1}\right)$ at $100^{\circ} \mathrm{C}$ for $2 \mathrm{~h}$ under reflux. After cooling the solution, the material was filtered with water until $\mathrm{pH}=8$ and dried at $80{ }^{\circ} \mathrm{C}$ for $12 \mathrm{~h}$. The material was named CLR (ㅡalcined and Leached Rice Husk Ash).

\section{Synthesis of MCM-22P precursor}

The protocol for the synthesis of MCM-22P precursor was adapted from the literature. ${ }^{23}$ Then, $0.74 \mathrm{~g}$ of $\mathrm{NaOH}$ and $0.74 \mathrm{~g}$ of $\mathrm{NaAlO}_{2}$ were dissolved in $162.40 \mathrm{~g}$ of distillated water. After, 4.99 $\mathrm{g}$ of hexamethyleneimine (HMI) used as the structure directing agent (SDA) and $12.00 \mathrm{~g}$ of CR or CLR were added to the mixture. The resulting slurry with theoretical Si/Al molar ratio $=22$ was stirred for $2 \mathrm{~h}$ and hydrothermally treated in PTFE-lined stainlesssteel autoclave in dynamic mode (tumbling at $60 \mathrm{rpm}$ ) at $135^{\circ} \mathrm{C}$ for 7 days. The autoclave was cooled to RT and the solid residue recovered though filtration. The white solid was washed with distilled water until $\mathrm{pH}=7$ and dried for $12 \mathrm{~h}$ at $60^{\circ} \mathrm{C}$. The materials were named $x$-MCM-22P being $x$ used for the silica source, $\mathrm{CR}$ or CLR. After calcination at $580^{\circ} \mathrm{C}$ for $12 \mathrm{~h}$ the tridimensional zeolite was obtained and named $x-M C M-22$.

\section{Swelling of CR-MCM-22P}

Swelling was performed by using $9.00 \mathrm{~g}$ of aqueous slurry of CR-MCM-22P (20 wt\% solid) and $35.00 \mathrm{~g}$ of an aqueous solution of 29 wt\% cetrimonium bromide $\left(\mathrm{C}_{16} \mathrm{TABr}\right)$ and $11.1 \mathrm{~g}$ of an aqueous solution of 25 wt\% tetrapropylammonium hydroxide (TPAOH). The resultant slurry was heated in a closed Teflon vessel at $80{ }^{\circ} \mathrm{C}$ for $18 \mathrm{~h}$ under magnetic stirring. The swollen precursor was filtered and the solid washed with distilled water until $\mathrm{pH}=9$ and dried at $60{ }^{\circ} \mathrm{C}$ for overnight. The obtained material was named CR-MCM-22P-Sw.

\section{Pillaring of swollen material}

The swollen precursor was added to tetraethyl orthosilicate (TEOS, $98 \%$ ), 1:5 wt/wt, at $80^{\circ} \mathrm{C}$ for $24 \mathrm{~h}$ under vigorous stirring and argon atmosphere. ${ }^{24}$ The obtained solid was hydrolyzed with water, $1: 50 \mathrm{wt} / \mathrm{wt}$ at $40{ }^{\circ} \mathrm{C}$ for 12 hours and dried at $60{ }^{\circ} \mathrm{C}$ for overnight. Calcination was done in tubular Pyrex reactor up to $550{ }^{\circ} \mathrm{C}$ (heating rate of $3{ }^{\circ} \mathrm{C} \mathrm{min}-1$ under argon flow) followed by 8 hours under air flow. The obtained material was named CRMCM-36.

\section{Synthesis of CR-MCM-49}

Synthesis of MCM-49 was realized similarly to the synthesis of MCM-22P (described above) using $\mathrm{CR}, 0.72 \mathrm{~g} \mathrm{NaOH}$ and $0.63 \mathrm{~g}$ $\mathrm{NaAlO}_{2}$, resulting in a slurry with a theoretical Si/Al molar ratio of 13. The obtained material was named CR-MCM-22[49].

\section{Desilication of CR-MCM-49}

The procedure was adapted from the literature. ${ }^{11 \mathrm{~b}}$ Calcined CR-MCM-49 (4.5 g) was added to a solution of $75 \mathrm{~mL}$ of aqueous $\mathrm{C}_{16} \mathrm{TABr}\left(0.1 \mathrm{~mol} \mathrm{~L}^{-1}\right)$ and $75 \mathrm{~mL}$ of aqueous $\mathrm{NaOH}\left(0.4 \mathrm{~mol} \mathrm{~L}^{-1}\right)$ under magnetic stirring at $70{ }^{\circ} \mathrm{C}$ for $2 \mathrm{~h}$ under reflux. The obtained solid was filtered until pH equal 8 and dried at $60^{\circ} \mathrm{C}$ for 12 h. The desilicated material was named CR-MCM-22[49]D.

\section{Cation exchange}

The acidic form of the obtained materials was achieved through three consecutive ion exchange cycles using through adding $1 \mathrm{~g}$ of zeolite to a $50 \mathrm{~mL}$ of $1.0 \mathrm{~mol} \mathrm{~L}-1$ aqueous $\mathrm{NH}_{4} \mathrm{NO}_{3}$ solution at ambient temperature for $3 \mathrm{~h}$. Subsequent calcination was performed at $500{ }^{\circ} \mathrm{C}$ (heating rate of $5^{\circ} \mathrm{C} \mathrm{min}^{-1}$ ) for $2 \mathrm{~h}$ under air atmosphere.

\section{Catalytic test}

Acetalization of benzaldehyde with pentaerythritol: benzaldehyde $(0.54 \mathrm{~g}, 5.00 \mathrm{mmol})$, pentaerythritol $(0.34 \mathrm{~g}, 2.50 \mathrm{mmol})$, and toluene $(2.00 \mathrm{~mL})$ were mixed and charged with $10 \mathrm{mg}$ of the acidic catalyst in a $10 \mathrm{~mL}$ flask equipped with a reflux condenser. The reaction was carried out under magnetic stirring for $2 \mathrm{~h}$ at $110^{\circ} \mathrm{C}$. After cooling to room temperature, the reaction mixture was diluted with $4 \mathrm{~mL}$ of dimethylformamide. The diluted mixture was filtered to remove the catalyst before being analysed using a GC-FID (equipped with DB-5 column, Agilent J\&W) to determine the benzaldehyde conversion.

\section{Characterization}

Powder XRD patterns of synthesized materials were analyzed on Rigaku Ultima IV diffractometer, using Cu-K $\alpha 1$ radiation in the regions of $2 \theta=3-40^{\circ}$ with step size of 0.02 .

Nitrogen adsorption and desorption isotherms at $-196{ }^{\circ} \mathrm{C}$ were measured with a Micromeritics ASAP 2010 manometric adsorption analyzer. Before the measurements were taken, the 
samples were degassed for $12 \mathrm{~h}$ at $300{ }^{\circ} \mathrm{C}$. The specific surface area $\left(S_{B E T}\right)$ was calculated by the BET method ${ }^{25}$ from the nitrogen adsorption data in the relative pressure range from 0.06 to 0.11 . The microporous volume $\left(V_{\text {micro }}\right)$ was estimated using the $t$-plot method. ${ }^{26}$ The pore size distribution was obtained Non Localized Density Functional Theory (NLDFT) method.

Cross-polarization, magic-angle spinning ${ }^{13} \mathrm{C}$ and ${ }^{29} \mathrm{Si}$ nuclear magnetic resonance spectroscopy (CP/MAS NMR) and ${ }^{27} \mathrm{AI}$ MAS NMR were performed on an Agilent $500 \mathrm{MHz}$ DD2 model.

Elemental analysis was determined by atomic absorption spectroscopy (AAS) on an AAnalyst 200, PerkinElmer after dissolution of the solids in $\mathrm{HNO}_{3} / \mathrm{HF}$ solution.

Thermogravimetric analyses (TGA/DTA) were performed on a TA Instruments Thermal Analysis Q50 with air using ramp of 20 ${ }^{\circ} \mathrm{C} \mathrm{min}^{-1}$ from 25 to $800{ }^{\circ} \mathrm{C}$.

Scanning electron microscopy (SEM) analyses were recorded on a JEOL JSM-6390LV microscope operating at $15 \mathrm{kV}$.

High resolution transmission electron microscopy (TEM) was used to determine the texture and morphology of the samples. A Philips CM 120 microscope equipped with a LaB $_{6}$ filament was used.

The acidity of materials was characterized through Fourier Transform Infrared spectroscopy (FT-IR) of chemisorbed pyridine on samples. Spectra were recorded on a Nicolet Magna 550-FT-IR spectrometer with a $2 \mathrm{~cm}^{-1}$ optical resolution. The zeolites were first pressed into self-supporting wafers (diameter: $1.6 \mathrm{~cm}, 20$ $\mathrm{mg}$ ) and pretreated at $450{ }^{\circ} \mathrm{C}$ under vacuum in an IR cell connected to a vacuum line. Pyridine adsorption was carried out at $150{ }^{\circ} \mathrm{C}$. The cell was then evacuated at $350{ }^{\circ} \mathrm{C}$ to remove all physisorbed pyridine. The amount of pyridine adsorbed on the Brønsted and Lewis sites was determined by integrating the band areas at respectively 1545 and $1454 \mathrm{~cm}^{-1}$ and using the extinction coefficients $\varepsilon\left(1545 \mathrm{~cm}^{-1}\right)=1.13$ and $\varepsilon\left(1454 \mathrm{~cm}^{-1}\right)=1.28 \mathrm{~cm} \mathrm{~mol}^{-}$ ${ }^{1}$, measured at $20^{\circ} \mathrm{C} .{ }^{27}$

\section{RESULTS AND DISCUSSION}

\section{Silica sources}

The silica sources CR and CLR were obtained through calcination and leaching, respectively. Both samples present a broad diffraction band at $15-30^{\circ}$ 2theta, which indicates that calcina- tion and leaching procedures yield only amorphous silica (Figure 1). Acid leaching of $C R$ was performed in order to remove the main oxide impurities $\left(\mathrm{K}_{2} \mathrm{O}, \mathrm{CaO}, \mathrm{MgO}, \mathrm{Fe}_{2} \mathrm{O}_{3}\right)$ present in the rice husk silica. AAS results prove the presence of $\mathrm{K}^{+}, \mathrm{Mg}^{2+}, \mathrm{Ca}^{2+}$ and $\mathrm{Fe}^{3+}$ with concentrations of $1320,130,80$ and $71 \mathrm{mg} \mathrm{g}^{-1}$ for CR, respectively. The CLR sample presents lower concentrations of these cations, which amount to 580, 40, 23 and $19 \mathrm{mg} \mathrm{g}^{-1}$. CHN elemental analysis of CR and CLR silicas showed 0.85 and 0.33 wt\%, respectively, which confirms the full removal of organic content.

Both CR and CLR present type II nitrogen adsorption isotherms recorded at $-196{ }^{\circ} \mathrm{C}$ (Figure S1) that are characteristic for non-porous materials ${ }^{28}$, featuring $\mathrm{S}_{B E T}$ of $90 \mathrm{~m}^{2} \mathrm{~g}^{-1}$ and $140 \mathrm{~m}^{2} \mathrm{~g}$ ${ }^{1}$, respectively. Yalçin et al. ${ }^{29}$ observed that through increasing the specific surface area of silica their reactivity is enhanced, which can lead to superior nucleation and crystallization rate of zeolites.

\section{Synthesis of CR-MCM-22 and CLR-MCM-22}

The sample obtained using both CR and CLR allows to observe the development of characteristic diffraction peaks of the MWW structure centered at 7.1, 8.0, 10.0, 25.1 and 26.1 '2theta, which correspond to the planes: (100), (101), (102), (220) and (310). ${ }^{30}$ The XRD pattern of CR-MCM-22 presents peaks of stronger intensity compared to CLR-MCM-22 (Figure 1). Indeed, by comparing the (310) diffraction plane CR-MCM-22 a 4.2 higher intensity with respect to CLR-MCM-22 can be inferred, which indicates that the CR-MCM-22 material is of higher crystallinity. This result is rather surprising as CLR was described as the more reactive silica source. ${ }^{29}$ 


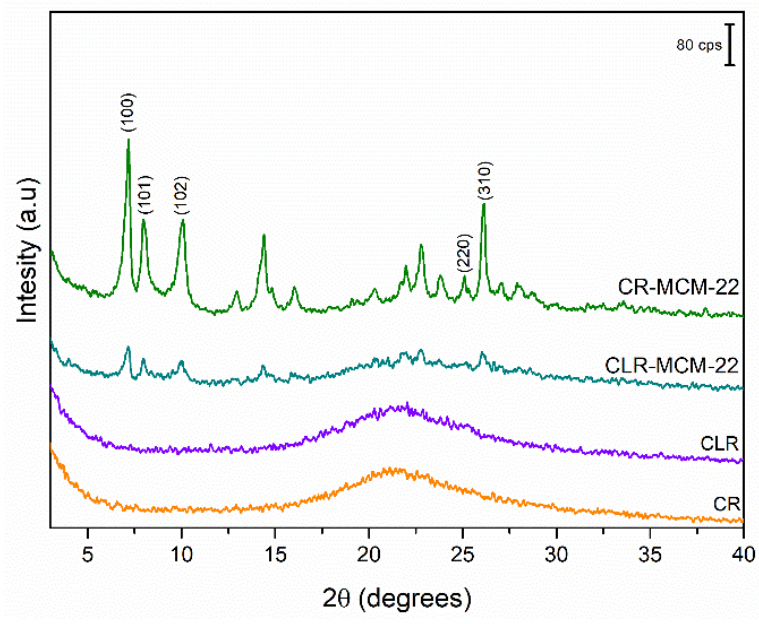

Figure 1. XRD patterns of MCM-22 zeolites synthesized with CR and CLR as the silica source.

\section{Study of the crystallization kinetics of MCM-22 materails}

The crystallization kinetics of MCM-22P using CR as silica source was studied through quenching the synthesis after 1, 34 and 7 days of synthesis and are present in Figure 2. Crystallization initiates within 4 days of hydrothermal synthesis, which is observed through the appearance of the characteristic diffraction peaks of the MWW structure. For the precursor samples, the diffraction peaks centered at $=3.3$ and $6.6^{\circ} 2$ theta correspond to the (001) and (002) reflection planes, which are due to the MWW zeolitic lamellar stacking along the $c$-axis and agree with the $d_{001}$ spacing of $2.7 \mathrm{~nm}$. This means that the thickness of each individual lamellae of $2.5 \mathrm{~nm}$, which is separated by silanol groups between lamellae with a typical size of $0.2 \mathrm{~nm}$. The silanol groups interact through hydrogen bonds with the SDA which allows for the stacking of the MWW lamellae. ${ }^{31}$ After calcination, the (001) and (002) peaks are no longer observable as a result of the condensation of silanol groups and the combustion of the SDA allowing for the development of the three-dimensional CR-MCM-22.

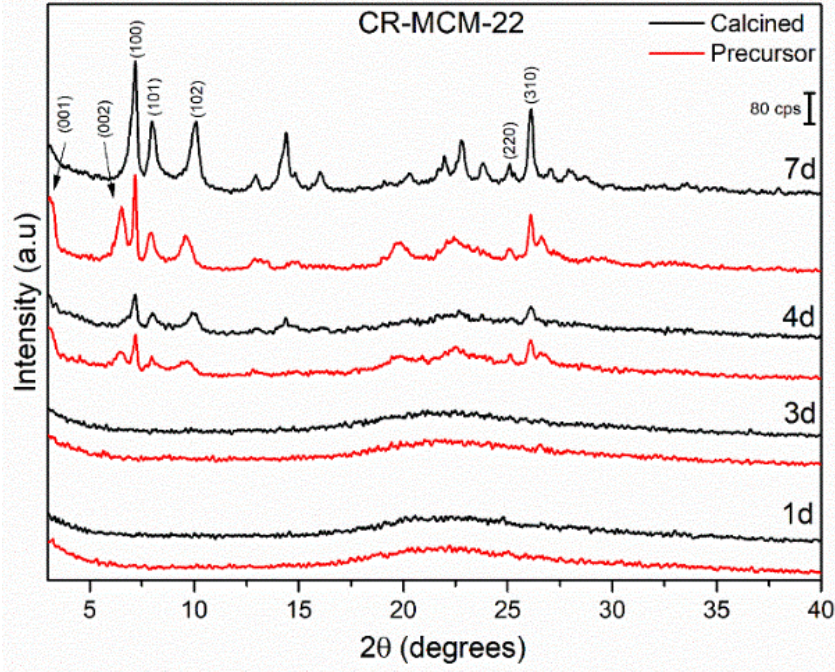

Figure 2. XRD patterns of CR-MCM-22P and CR-MCM-22 samples quenched at the indicated time of hydrothermal synthesis.

Opposing to what was expected, the use of the leached CR $(C L R)$ as silica source did not allow for increasing the crystallization kinetics. Indeed, from the XRD patterns (Figure 3) it was observed that characteristic peaks are present only after 7 days of synthesis. Moreover, the intensity of the peak corresponding to the (310) diffraction plane for CLR-MCM-22-7d featured similar intensity to the peak observed for CR-MCM-22-4d. This finding indicates that crystallization merely started at day 7 of synthesis using CLR as silica source.

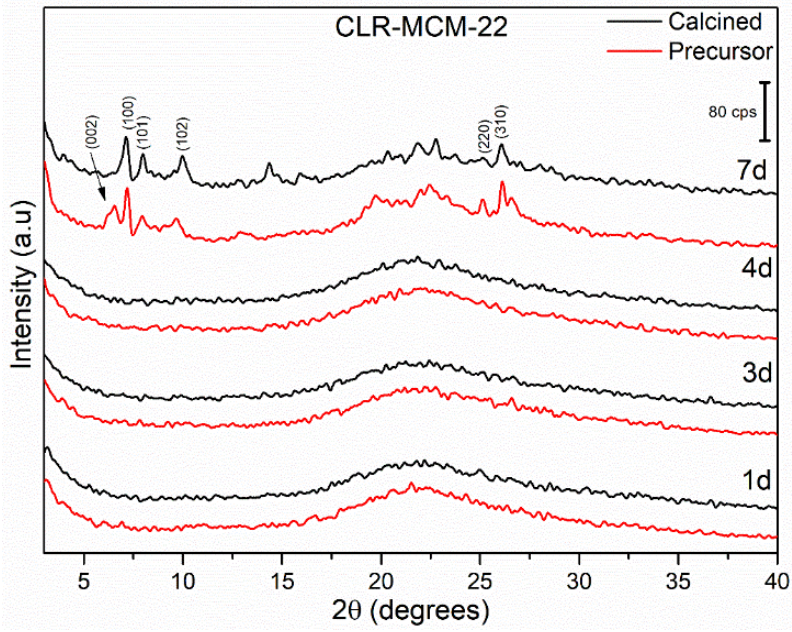

Figure 3. XRD patterns of CLR-MCM-22P and CLR-MCM-22 samples quenched at the indicated time of hydrothermal synthesis.

The surprisingly faster crystallization kinetics of CR-MCM-22 might be explained through the presence of alkaline and alkaline earth metal oxides present in $C R$ and which are removed through the acid leaching in order to obtain CLR. We hence suggest that 
these cations play a key role for the nucleation and crystallization in the gel mixture. Indeed, the reaction of alkali metal (M) oxides with water $\mathrm{M}_{2} \mathrm{O}+\mathrm{H}_{2} \mathrm{O} \rightarrow 2 \mathrm{MOH}$ and alkaline earth metal oxides with water $\mathrm{MO}+\mathrm{H}_{2} \mathrm{O} \rightarrow \mathrm{M}(\mathrm{OH})_{2}$ is prone to increase the $\mathrm{OH}^{-}$ concentration and hence the silica solubility. It is interesting to note that the concentration of metallic cations in the CR-MCM$22 \mathrm{P}-7 \mathrm{~d}$ sample showed presence of $\mathrm{K}^{+}, \mathrm{Mg}^{2+}, \mathrm{Ca}^{2+}$ and $\mathrm{Fe}^{3+}$ cations, which concentration amounts of $410,110,45$ and $68 \mathrm{mg} \mathrm{g}^{-1}$, respectively. This result strongly suggests that these metal cations act as charge compensating cations in the zeolite structure.

The recoding of infrared spectra were recorderd in order to achieve valuable information on the vibration of $\mathrm{TO}_{4}$ groups of zeolites. Specifically, zeolites with MWW structure feature secondary building units formed by double 6-rings $\mathrm{TO}_{4}$ tetrahedra that connect the hemicavities of the upper and lower surfaces of each MWW lamellae. The presence of these building units give characteristic vibrational bands that are centered at 600 and 555 $\mathrm{cm}^{-1} .^{23}$ For CR-MCM-22P these bands appear for the sample quenched after three days as shown in Figure S2 (image a), which suggests that these building units are formed within the first two days of the crystallization. Through increasing crystallization time the intensity of these bans further evolves. For the CLR-MCM-22P sample the characteristic bands emerge after 4 days of crystallization, as shown in Figure $\mathbf{S 2}$ (image b).

The ${ }^{13} \mathrm{C}$ MAS NMR was performed in order to evidence the presence of the SDA within the CR-MCM-22P sample (Figure 4). As can be observed the characteristic peaks of $\mathrm{HMI}$ can be deduced, indicating the integrity of the organic template after the synthesis within the structure.

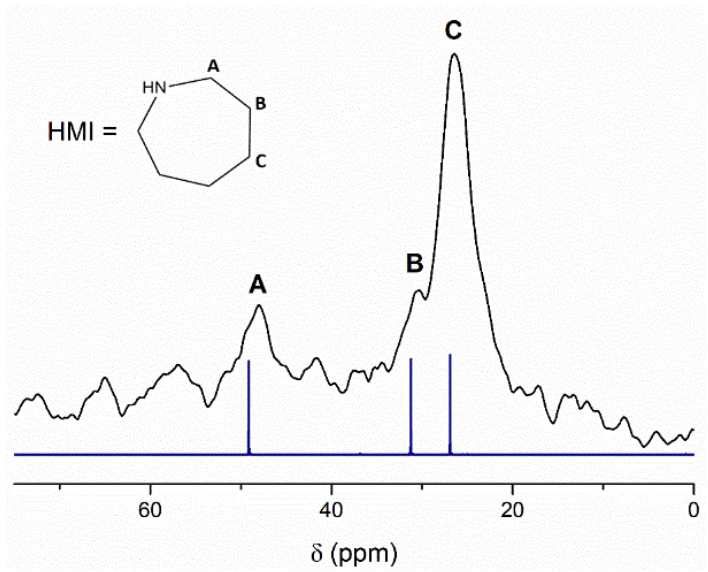

Figure 4. ${ }^{13} \mathrm{C} C P / M A S ~ N M R$ of the CR-MCM-22P sample. The lower blue spectrum corresponds to the signals observed in the ${ }^{13} \mathrm{C}$ liquid NMR of HMI recoded in Chloroform-D1.
To elucidate the formation of channels and cavities of the MCM-22P samples using CR and CLR as silica sources and to determine the location of the occluded organic template, TGA/DTA analyses were performed (Figure S3). The observed weight losses can be separated into four distinct events: (i) - the removal of water, which is physically adsorbed on the surface of the material $\left(25-140{ }^{\circ} \mathrm{C}\right)$; (ii) - the combustion of $\mathrm{HMI}$ molecules present in 12-MR hemicavities on the MWW lamellae (140 $\left.320^{\circ} \mathrm{C}\right)$; (iii) - the combustion of HMI molecules occluded in 10 MR sinusoidal channels in the MWW lamella $\left(320-510{ }^{\circ} \mathrm{C}\right) ;(i v)-$ the combustion of $\mathrm{HMI}$ molecules strong interacted and the dehydroxylation of silanol groups present on the surface of zeolite structure $\left(510-800^{\circ} \mathrm{C}\right)$.

CR-MCM-22P lead to a total loss of 16.59 wt\%, which is twice of that observed for the CLR-MCM-22P sample (8.72 wt\%), which confirms the faster crystallization using CR as silica source. Moreover, it was observed that the weight losses of the CRMCM-22P steadily increases, indicating the gradual incorporation of the SDA to the zeolite structure. These results compare well to what has already been evidenced from the XRD results. For the CLR-MCM-22P sample, a similar behavior was observed after 4 days of crystallization. It was further observed for CR-MCM-22P that the loss event (iii) is higher compared to the event (ii) $(4.95$ wt\% and $3.05 \mathrm{wt} \%$, respectively, which suggest that more $\mathrm{HMI}$ molecules are accommodated in the lamellae than on the MWW surface. The CHN analysis of CR-MCM-22P infers 13.76 wt\%, which is close of the loss of 13.46 wt\% obtained with the events (ii - iv) observed in TGA (Table S1). Similar is observed for CLRMCM-22P.

The $\mathrm{N}_{2}$ adsorption and desorption isotherms at $-196{ }^{\circ} \mathrm{C}$ of $\mathrm{CR}-$ MCM-22 and CLR-MCM-22 are of type I, characteristic of microporous materials (Figure $\mathbf{5}$ and S4). An important $\mathrm{N}_{2}$ uptake at high relative pressures $(0.8)$ can be ascribed to the presence of intercrystalline porosity (larger mesopores or macropores). 

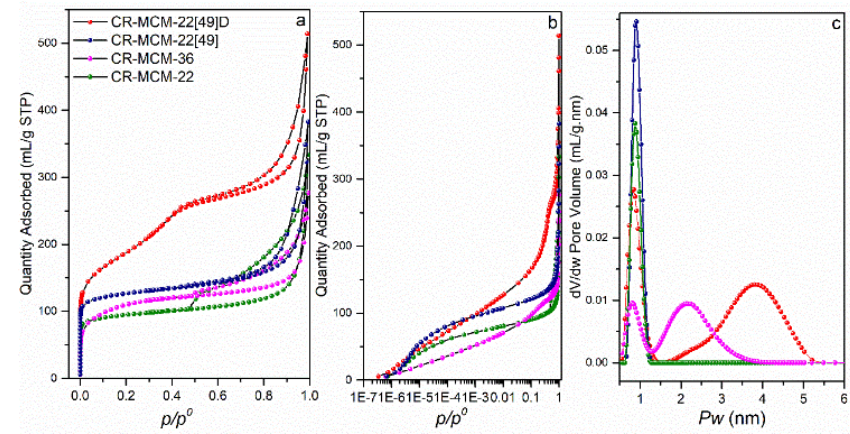

Figure 5. $\mathrm{N}_{2}$ adsorption and desorption isotherms at $-196{ }^{\circ} \mathrm{C}(\mathrm{a})$, logarithmic plot of $\mathrm{N}_{2}$ adsorption and desorption isotherms at $-196{ }^{\circ} \mathrm{C}$ (b) and NLDFT pore size distribution (c) of CR-MCM-22, CR-MCM-36, CR-MCM22[49] and CR-MCM-22[49]D materials.

The microporous volume of CR-MCM-22 and CLR-MCM-22 was calculated to be 0.10 and $0.01 \mathrm{~mL} \mathrm{~g}^{-1}$ (Table 1) respectively. CR-MCM-22 sample shows hysteresis loop of type H5, indicating the occurrence of cavitation, hence on the presence of occulted larger mesopores.

Table 1. Textural and chemical properties of synthesized materials.

\begin{tabular}{lccc}
\multicolumn{1}{c}{ SAMPLE } & Si/Al $^{a}$ & $\boldsymbol{V}_{\text {micro }}{ }^{\boldsymbol{b}}$ & $\boldsymbol{V}_{\boldsymbol{T} \boldsymbol{p}^{\boldsymbol{b}}}$ \\
\hline CR-MCM-22 & 19 & 0.10 & 0.52 \\
CLR-MCM-22 & 16 & 0.01 & 0.12 \\
CR-MCM-36 & 49 & - & 0.43 \\
CR-MCM-22[49] & 10 & 0.14 & 0.59 \\
CR-MCM-22[49]D & 7 & 0.07 & 0.80 \\
\hline
\end{tabular}

${ }^{\text {a }}$ determined by $A A S ;{ }^{b}\left(\mathrm{~mL} \mathrm{~g}^{-1}\right)$

From the SEM images of CR-MCM-22P particles of various sizes were observed (Figure 6ab). These particles are composed of platelet crystals with lengths of $\sim 0.5 \mu \mathrm{m}$ featuring edge-toface orientation, which is typical of the MWW structure. From Figure $\mathbf{6 b}$ the presence of cobweb-like fibrous structures was further evidenced.

As far as the SEM image of CLR-MCM-22P are concerned, particles of different dimensions with smooth surfaces can be observed (Figure 6c). At higher magnification (Figure 6d), these particles feature thin platelet crystals and absence of fibrous structure. Additionally, to the morphological difference of CRMCM-22P and CLR-MCM-22P particles, CR-MCM-22P particles are larger. This is in agreement to what was observed in $\mathrm{N}_{2}$ physisorption were a more important intracrystalline porous volume was deduced.
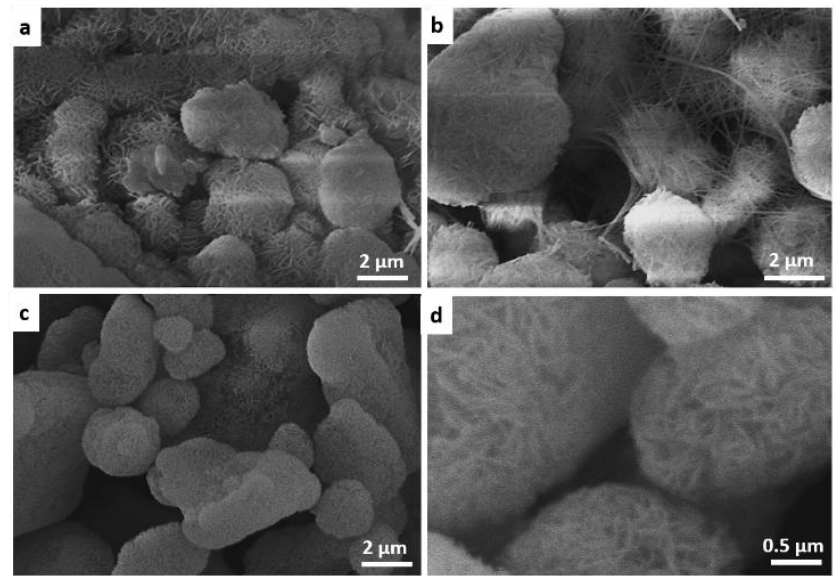

Figure 6. SEM micrographs of CR-MCM-22P (a) and (b) and CLR-MCM-22P (c) and (d).

To examine the chemical nature of aluminum species in the CR-MCM-22 sample, ${ }^{27} \mathrm{Al}$ MAS NMR spectra were recorded and the (Figure 7a). It is well known that framework aluminum species (Al(OSi)4 units lead to a signal at approximately $60 \mathrm{ppm}$. Extraframework aluminium species (octahedral Al) lead to a signal at $10-0 \mathrm{ppm}$. The spectra of CR-MCM-22 reveals that most of the species (75\%) are tetrahedrally coordinated and located most probably in the zeolite framework. This result compares well to MCM-22 obtained through commercial silica sources. ${ }^{11 a}$

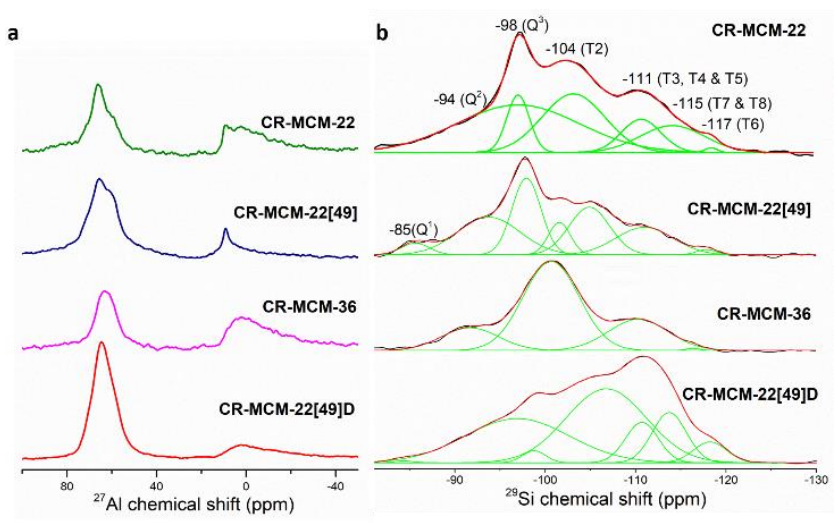

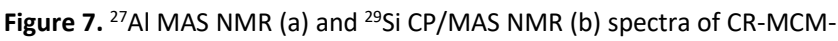
22, CR-MCM-49[22], CR-MCM-36 and CR-MCM-22[49]D samples.

To investigate the evolution of T-sites ( $\mathrm{Si}, \mathrm{Al}$ ) in CR-MCM-22, ${ }^{29} \mathrm{Si}$ CP/MAS NMR analysis was further performed (Figure 7b). The MWW structure features eight nonequivalent crystallographic T-site positions (Figure S5). The main region between -104 - $130 \mathrm{ppm}\left(\mathrm{Q}^{4}\right.$ sites) shows overlapped resonances which belongs to the different crystallographic T-sites with accuracy of \pm 0.2 ppm: -118 ppm (T6), -115 ppm (T7 + T8), -111 ppm (T3, T4 and 
T5), $-102 \mathrm{pm}(\mathrm{T} 2)$. The resonance at $-98 \mathrm{ppm}$ is attributed to the $\mathrm{T} 1$ groups and the $\mathrm{Q}^{3}$ sites which is characteristic of silanol defects $\left[\mathrm{Si}(\mathrm{OH})(\mathrm{OSi})_{3}\right.$ or $\left.\mathrm{Si}(\mathrm{OH})(\mathrm{OAI})(\mathrm{OSi})_{2}\right]$. Moreover, the resonance at $-94 \mathrm{ppm}$ is attributed of $\mathrm{Q}^{2}$ sites and also characteristic of silanol defects $\left[\mathrm{Si}(\mathrm{OH})_{2}(\mathrm{OSi})_{2}, \mathrm{Si}(\mathrm{OH})_{2}(\mathrm{OAI})(\mathrm{OSi})\right]$, which are characteristic of MCM-22. ${ }^{32}$ The quantitative data of each peak are shown in Table S1.

\section{Optimal MCM-22 synthesis conditions using CR}

In order to study the impact of the chemical composition of the synthesis gel on the synthesis of MCM-22P using CR was performed with varying the $\mathrm{Si} / \mathrm{Al}$ molar ratios of the synthesis gel to 13,50 and 100 . Additionally, the MCM-22P synthesis was performed under static conditions at 135 and $150{ }^{\circ} \mathrm{C}$. As far as the Si/Al ratio of the synthesis gel is concerned, only the synthesis with a gel composition of $\mathrm{Si} / \mathrm{Al}=22$ allowed for the development of the desired MCM-22P (Figure S6). Moreover, only synthesis under tumbling conditions allow for successful MWW crystallization. These results confirm that the synthesis of MCM$22 \mathrm{P}$ critically depends on both the $\mathrm{Si} / \mathrm{Al}$ molar ratio and agitation.

\section{Synthesis of MCM-49 using CR}

In order to widen the possible use of CR as alternative silica source for MWW-type materials, the synthesis of MCM-49 was investigated. The tridimensional MCM-49 zeolite have firstly been obtained through direct synthesis through adjusting the molar ratio of SDA and inorganic cations to blow 2 in the synthesis mixture. ${ }^{33}$

From the XRD pattern of the obtained materials it was observed that the use of CR as silica source led to the development of $(00 /)$ diffraction peaks characteristic of the MWW lamellar zeolitic precursor (Figure 8). Hence, MCM-22P was achieved instead as to the expected tridimensional MCM-49.

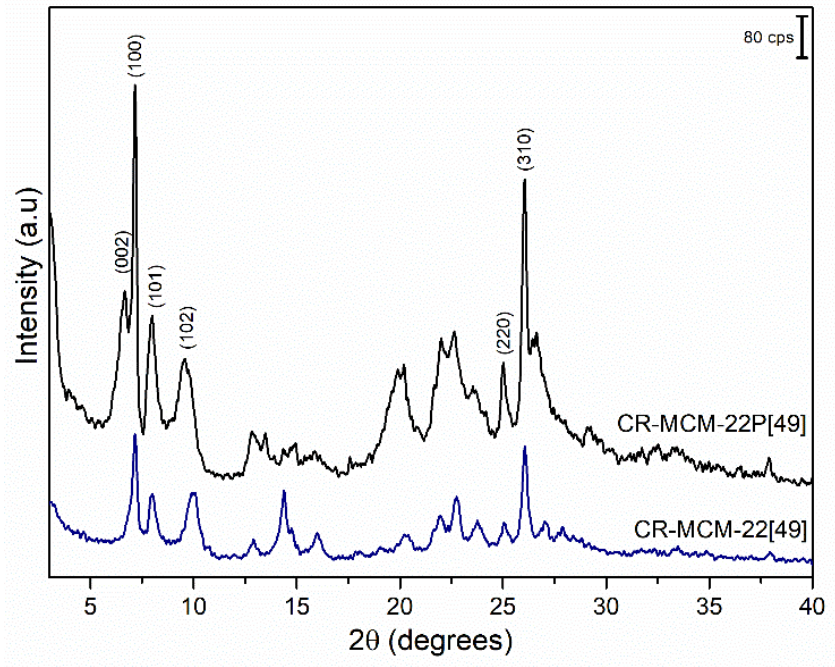

Figure 8. XRD patterns of the obtained materials with the synthesis procedure of MCM-49, CR-MCM-22P[49] and CR-MCM-22[49].

The formation of a lamellar zeolitic precursor with the MCM49 synthesis procedure could be attributed to the presence of alkali cations in CR silica source, which may act as structure directing ions, and may thus favor the development of certain zeolite structures. Indeed, it was previous reported that the presence of $\mathrm{K}^{+}$ions in the synthesis of $\mathrm{MCM}-49$ favored the formation of MCM-22P. ${ }^{34}$ Presence of $\mathrm{K}^{+}$ions in CR silica source (1320 $\mathrm{mg} \mathrm{g}^{-1}$ ) conforms well these results. In addition, it was observed that the increase of $\mathrm{OH}^{-}$concentration is necessary to increase the aluminum content for Si/Al molar ratio $=13$. The MCM-22P obtained with the MCM-49 procedure was named CRMCM-22P[49] and after calcination CR-MCM-22[49]. Regarding the intensity of the (310) diffraction peak, the CR-MCM-22[49] showed same intensity of the CR-MCM-22 that confirms its high crystallization (Figure 8).

From the TGA results of CR-MCM-22P[49] (Figure S3) a total loss of 29.03 wt\% was deduced, which corresponds to almost twice that the observed for CR-MCM-22P. This finding confirms that the increase of $\mathrm{NaOH}$ and aluminum content (Si/Al molar ratio $=13)$ favors the incorporation of the organic template in the zeolitic structure. Specifically, the event (iii), characteristic of the combustion of the HMI occluded in 10-MR sinusoidal channels showed similar values of with 4.95 and 5.92 wt\% for CR-MCM22P and CLR-MCM-22P[49], respectively. Moreover, a significant difference was observed at $140-320^{\circ} \mathrm{C}$ (event ii) where the loss 
was 3.05 and $9.90 \mathrm{wt} \%$ for those samples and confirms that most of HMI molecules are occluded between MWW lamellae. This results it is in agreement with a previous studies where high $\mathrm{Al}$ MWW-type materials ( $\mathrm{Si} / \mathrm{Al}=13$ - 10) showed Al incorporation on the lamellae, specifically at the crystallographic T6 sites, because the amount of $\mathrm{Al}$ is greater to be accommodated in the lamellae. ${ }^{7 a}$ Moreover, an excess of HMI template may exists that could be accommodated on the MWW lamellae with their interaction via hydrogen bonding with silanol groups located on the surface.

The $\mathrm{N}_{2}$ adsorption and desorption isotherm at $-196{ }^{\circ} \mathrm{C}$ of $\mathrm{CR}-$ MCM-22[49] (Figure 5a) are of the type I isotherm that confirms its microporous nature. Moreover, a sharp $\mathrm{N}_{2}$ uptake at relative pressures higher than $\mathrm{p} / \mathrm{p}^{0}=0.8$ was observed, which is characteristic of intercrystalline porosity (larger mesopores or macropores). The microporous volume for the CR-MCM-22[49] was $0.14 \mathrm{~mL} \mathrm{~g}^{-1}$, with is more important than that achieved for CR-MCM-22 (Table 1).

The ${ }^{27} \mathrm{Al}$ MAS NMR spectra of CR-MCM-22[49] allow to deduce that most of the aluminum species (74 \%) are of tetrahedral coordination even though the aluminum content was increased $(\mathrm{Si} / \mathrm{Al}=10)$, which is similar of the CR-MCM-22 sample. The ${ }^{29} \mathrm{Si}$ CP/MAS NMR spectrum of CR-MCM-22[49] shows a less diffuse resonance at -94 ppm ( $Q^{2}$ species), (Figure $7 \mathbf{b}$ ). In addition, a new peak emerged at -85 ppm of low relative percentage (6.6 \%) appears, which falls in the $Q^{1}$ region, which is associated with the increase of aluminum content in the zeolite. The development of a new peak was further observed at $-102 \mathrm{ppm}$ and is characteristic of silanol groups at framework defects sites and/or on the external surface of MWW crystals. ${ }^{35}$ The Table S1 shows that the relative percentage area of the peak at -98 ppm increases, which corresponds to a more important incorporation of aluminum in $\mathrm{T} 1$ positions and $\mathrm{Q}^{3}$ species attributed to the isolated silanol defects $\left[\mathrm{Si}(\mathrm{OH})(\mathrm{OSi})_{3}\right.$ or $\mathrm{Si}(\mathrm{OH})(\mathrm{OAI})(\mathrm{OSi})_{2}$. Furthermore an increase in the intensities of T3 - T5; T7, T8 and T6 sites was observed, which indicates the favored population of aluminum in these T-sites. These results are well supported by the ${ }^{27} \mathrm{Al}$ MAS NMR spectra, where no increase in the relative proportion of nonframework aluminum was observed for CR-MCM-22[49].
Synthesis of hierarchical MWW-type zeolites from CR-MCM22P and CR-MCM-22[49] materials.

Hierarchical zeolites combining mesopores with their intrinsic microporosity and allow hence for improving the accessibility of bulky reactant, intermediate and product molecules. ${ }^{36}$ Two ways in order to obtain hierarchical zeolites is pillaring of lamellar zeolites or desilication. Whilst the pillaring of lamellar zeolites allows for increasing the space between these, desilication permits for the formation of intracrystalline mesoporosity through dissolution of silicon framework species. CR-MCM-22P and CRMCM-22[49] were used as precursors to obtain pillared and desilicated hierarchical MWW-type zeolites, respectively.

The pillaring procedure is preceded by a swelling treatment where cationic surfactants with long alkyl-chains are intercalated between MWW lamellae. After that, the pillaring solution using silicon alkoxide was added and silica pillars are formed after calcination.

The swelling treatment of the CR-MCM-22P resulted in the overlapping of the (101) and (102) diffraction planes, yielding to a broad peak at $8-10^{\circ} 2$ theta (Figure 9). This indicates the partial loss of the vertical alignment order in the stacking direction along the $c$-axis. ${ }^{14}$

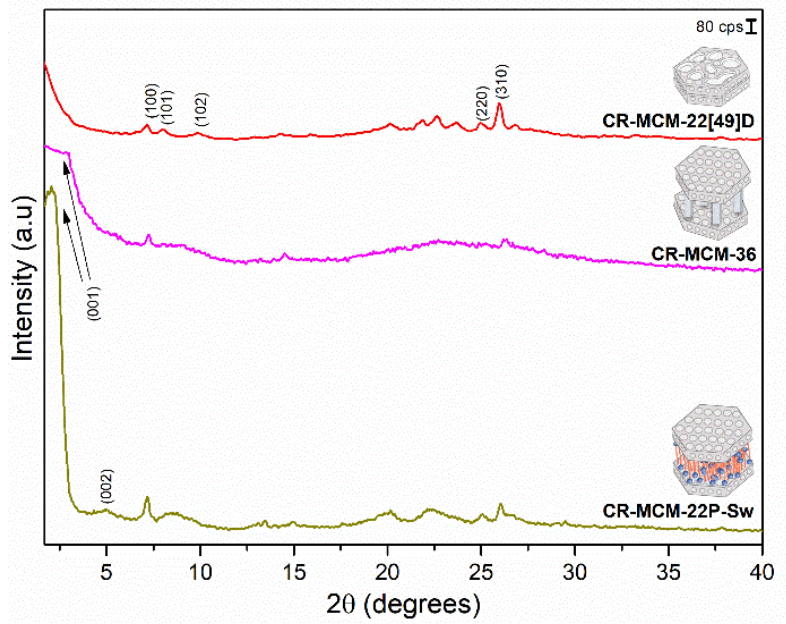

Figure 9. XRD patterns of the CR-MCM-22P-Swollen, CR-MCM-36 and CR-MCM-22[49]D materials.

It was observed the displacement of the (001) reflection plane at $2.0^{\circ} 2$ theta with the $d_{001}$ spacing of $4.4 \mathrm{~nm}$ results from surfactant molecules intercalated between MWW lamellae, as a result of the hybrid organic-inorganic MWW structure. The in- 
crease of the $\mathrm{d}_{001}$ spacing of $1.9 \mathrm{~nm}$ after the swelling procedure indicates that surfactants molecules are laterally accommodated between the MWW lamellae (considering the theoretical length of $\mathrm{C}_{16} \mathrm{TA}^{+}$with $\sim 2.0 \mathrm{~nm}$ ). After pillaring, the broadening of the (001) peak was observed, which indicates inhomogeneity of the stacking order of the lamellae. Moreover, a reduction of the (220) and (310) reflections is observed, which can be attributed to the increase of the amorphous silica content (pillars). The increase of the $\mathrm{Si} / \mathrm{Al}$ molar ratio $(\mathrm{Si} / \mathrm{Al}=49$ ) for $\mathrm{CR}-\mathrm{MCM}-36$ further supports these results.

From the ${ }^{27} \mathrm{Al}$ MAS NMR spectrum of CR-MCM-36 the relative proportion of aluminum in tetrahedral coordination in framework amounts to $54 \%$ (Figure 7a). Thus, the swelling and pillaring procedures remove framework aluminum species. Furthermore, the ${ }^{29} \mathrm{Si} \mathrm{CP} / \mathrm{MAS}$ NMR spectrum of CR-MCM-36 shows three broad peaks that falls in the region of the $Q^{2}, Q^{3}$ and $Q^{4}$ sites (Figure 7b). The relative percentage of $\mathrm{Q}^{3}$ sites increases in pillared sample (Table S1). This is associated with the partial dissolution of the zeolitic structure after the swelling procedure because the alkaline media partially dissolve the zeolitic structure, breaking the Si-O-Si linkages and generating silanol groups as defect sites. Moreover, the pillaring procedure leads to the formation of silica pillars between lamellae, which are additionally rich in silanol groups. The decrease of the quantitative data of T2; T7, T8 and T6 sites indicates the removing of aluminum of these positions, which is in agreement to what has been inferred from ${ }^{27} \mathrm{Al}$ MAS NMR, in which a decrease in the relative proportion of aluminum in framework positions after pillaring was observed.

The aim of the desilication procedures is to create intracrystalline mesopores by the removal of zeolitic units from the zeolites crystals without severe destruction of their structure. ${ }^{37}$ The XRD of the desilicated CR-MCM-22[49] sample is shown in Figure 9. The presence of the (100), (220) and (310) intracrystalline diffraction peaks of the MWW structure can be deduced and the intensity of the (310) diffraction peak is similar to that observed for CR-MCM-22[49]. Yet, the (100) peak is less intensive when compared with the CR-MCM-22[49] (Figure 3), which suggest that desilication removes zeolitic fragments from the (100) plane of the crystal preferentially. CR-MCM-22[49]D presents a Si/AI molar ratio of 7 for the, which confirms the desilication phenomena.

From the $\mathrm{N}_{2}$ adsorption and desorption isotherms at $-196{ }^{\circ} \mathrm{C}$ of the hierarchical CR-MCM-36 and CR-MCM-22[49]D materials an important $\mathrm{N}_{2}$ uptake at low $p / p^{0}$ can be observed, which is characteristic of the strong adsorbate-adsorbent interactions and/or micropore filling (Figure 4a). A step adsorption step between 0.12 and 0.4 of relative pressure can be ascribed to capillary condensation in mesopores, which result from the pillaring and desilication procedures. At low relative pressures a lower microporous volume can be deduced for CR-MCM-36 and CR-MCM-22[49]D compared to CR-MCM-22 and CR-MCM-22[49], which can be attributed of pillaring and desilication treatments (Figure 4b). The NLDFT pore size distribution for both samples CR-MCM-36 and CR-MCM-22[49]D allows for observing microand mesopores (Figure 4c). For the CR-MCM-36 sample supermicropores and small mesopores $(1.3-4 \mathrm{~nm})$ can be evidenced. In the case of sample CR-MCM-22[49]D, the pore size distribution is wider and comprised between $1.6-5 \mathrm{~nm}$, presenting a maximum centered at $3.8 \mathrm{~nm}$. With respect to microporosity (Table 1), the decrease of the microporous volume for the pillared sample CR-MCM-36 can be ascribed to the swelling procedure, in which the use of alkaline media at elevated temperatures is prone to lead to the degradation of some zeolitic lamellae. The pillaring procedure can further lead to the deposition of nonframework silica species on the MWW lamellae, which may obstruct some micropores. For the desilicated sample CR-MCM22[49]D, the microporosity decreases, which can readily be ascribed to the creation of mesopores to the expense of micropores. The desilication procedure has further an influence removing nonframework aluminum species as the relative proportion of aluminum in octahedral coordination reduces to $9 \%$ (Figure 7a). From ${ }^{29} \mathrm{Si} \mathrm{CP} / \mathrm{MAS}$ NMR it was further evidenced an increase in the amount of silanol defects $\left[\mathrm{Si}(\mathrm{OH})_{2}(\mathrm{OSi})_{2}\right.$, $\left.\mathrm{Si}(\mathrm{OH})_{2}(\mathrm{OAI})(\mathrm{OSi})\right]$ after desilication from the increase ein the resonance at $-94 \mathrm{ppm}$ and the and the decrease of the signal at 98 ppm (Figure 7b).

In order to further characterize the texture of the samples TEM images of CR-MCM-22 were recorded (Figure 10). Thin platelet crystals formed by the regular stacking of individual MWW lamellae in the $a b$ plane could be observed (Figure 10a). 
In Figure 10b is represented the TEM image of a set of three MWW crystals (high-density regions) in the $a b$ plane on some crystals oriented to the $c$ plane. Figure 10c presents the high resolution image taken to the $c$ plane from which the hexagonal pore system of high regularity was observed.

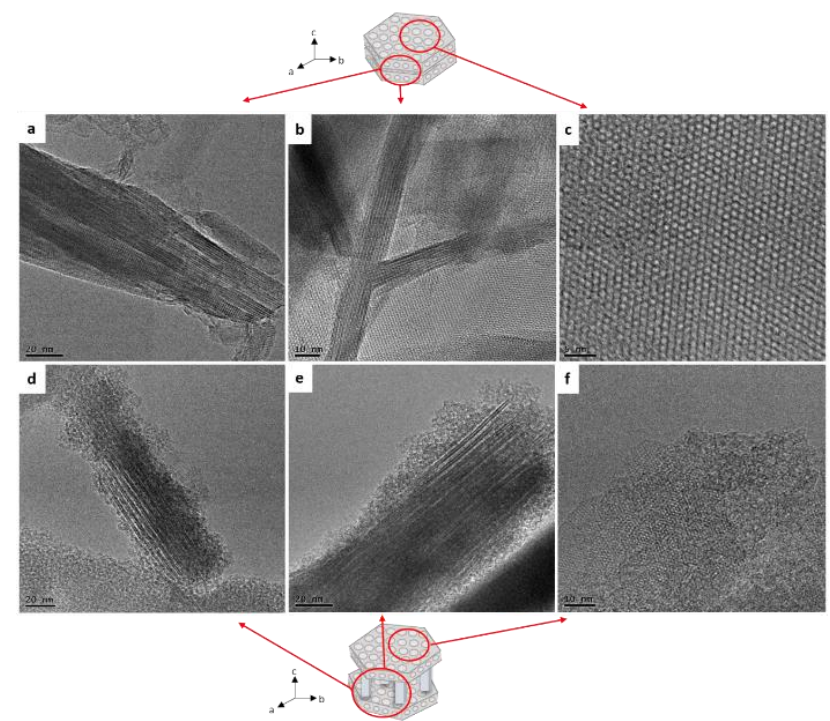

Figure 10. TEM images of CR-MCM-22 (a), (b) (c) and CR-MCM-36 (c), (d) and (f).

As far as the pillared sample is concerned (CR-MCM-36) the TEM images reveal a larger separation of MWW lamellae by regions of less density. These interlamellar regions range from 1.2 to $4.0 \mathrm{~nm}$, which is in agreement to what was already evidenced through $\mathrm{N}_{2}$ physisorption. From the TEM images it is yet difficult to inferred further information on the properties (lateral dimensions, periodicity, order) of the amorphous pillars, due to their amorphous nature. ${ }^{31}$ However, it is certain that the hemicavities between MWW lamellae surface are exposing after pillaring. Moreover, amorphous silica surrounding these sets of crystals were observed. The increase of silica content corroborates with the XRD of CR-MCM-36 sample in Figure $\mathbf{1 0}$ and the increase of Si/Al molar ratio after pillaring. From the Figure $10 \mathrm{f}$ the microporous system featuring hexagonal symmetry can be deduced. All these results confirmed that CR-MCM-36 combines micropores with interlamellar mesopores.

As far as CR-MCM-22[49] and its hierarchical derivative CRMCM-22[49]D are concerned the TEM images present the stacking of four crystals (with thickness of $20 \mathrm{~nm}$ ) that correspond to eight individual MWW lamellae regularly stacked (Figure 11a).
The images taken to the $c$ plane (Figure 11bc) allow to observe the regular crystal structure of the zeolite.

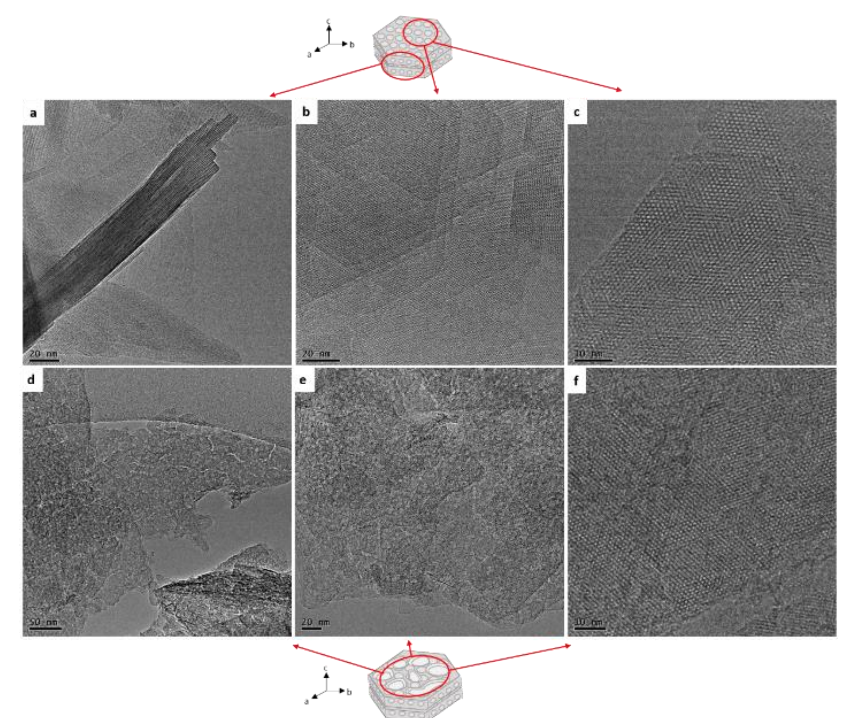

Figure 11. TEM images of CR-MCM-22[49] (a), (b) (c) and CR-MCM22[49]-desilicated (c), (d) and (f).

The effect of desilication procedure was observed in the TEM images taken to the $c$ plane (Figure 11def). The electron clear regions within the crystals correspond to the mesopores of rater homogeneous size distribution. These results foster what has been observed in from XRD (desilication preferentially of the (100) plane) and $N_{2}$ physisorption (NLDFT pore size distribution: $1.6-5 \mathrm{~nm}$ ). From Figure 11d it can further be deduced that the desilication process leads to mesopores that connect the outer surface of the crystal.

Acidity is a key parameter in zeolite catalysis. In order to achieve further insights on the nature and concentration of acidity of synthesized materials pyridine chemisorptions followed by IR spectroscopy was performed. Sample CR-MCM-22 (Si/AI = 19) presents 189 and $123 \mu \mathrm{mol} \mathrm{g} \mathrm{g}^{-1}$ Brønsted (BAS) and Lewis Acidity (LAS), respectively. For CR-MCM-22[49] an increase in both BAS and LAS was observed, which amount to 332 and 306 $\mu \mathrm{mol} \mathrm{g}^{-1}$. This observation can be ascribed to the increase of the aluminum content $(\mathrm{Si} / \mathrm{Al}=10)$ in the sample. In addition, the increase of aluminum content could also generate non framework aluminum after the cation exchange treatment with that could act as LAS and previously reported in the literature. ${ }^{7 a}$ Indeed, the BAS/LAS ratio is lower for CR-MCM-22[49] compared to CR-MCM-22. All samples showed similar profile with lower of BAS/LAS ratios with the increase of temperature, which indicates 
that nonframework aluminum species were gradually generated at higher of temperature.

The hierarchical pillared sample CR-MCM-36 (Si/AI = 49) showed the decrease acidic sites and confirms the silica pillars "diluted" the BAS. It was also observed that the BAS/LAS ratio decreases when compared with CR-MCM-22, which suggests that swelling and pillaring treatments increases the nonframework aluminum species content. The hierarchical desilicated CR-MCM22[49]D sample showed 1.3 times lower BAS with respect to $C R$ MCM-22[49]. Furthermore, the BAS/LAS of CR-MCM-22[49]D (0.6) is significantly lower than that of CR-MCM-22[49] (BAS/LAS $=1.1$.

By treating the pyridine chemisorbed samples at various temperatures $\left(250,350\right.$ and $\left.450^{\circ} \mathrm{C}\right)$ the strength of the acid sites can be inferred (Table S2). Here from it can be deduced, though featuring different BAS/LAS ratios, the strength of the sites is comparable for all samples.

\section{Catalytic performance}

Catalytic activity is influenced by the nature, amount, strength and accessibility of the acid sites present in the MWWtype zeolites. The acetalization reaction was chosen because of the following reasons: (i) high interest for in products derived from acetals in the context of renewable and degradable polymers because of their high oxygen to carbon ratio, ${ }^{38}$ (ii) classically acetalization reactions are mainly performed using mineral acids, which is associated with many environmental issues including toxicity, corrosion and difficulty of the separation from the reaction medium; (iii) There is a major interest by the fragrance and flavors industries to achieve acetals as main building blocks and final products; ${ }^{39}$ (iv) acetalization are often used as model reactions to evaluate materials with strong acid sites and hierarchical porous architectures; ${ }^{40}(v)$ The use of zeolites could provide a much cleaner technology for the production of acetals. ${ }^{41}$ To the best of our knowledge, this is first time that MWW-type zeolites were applied for this reaction.

The catalytic performance of the obtained materials for the reaction of acetalization of benzaldehyde with pentaerythritol is shown in Figure S7. The 10-ring sinusoidal entrance of the MWW zeolite $(0.41 \mathrm{~nm} \times 0.51 \mathrm{~nm})$ and the 10-ring elliptical $(0.40 \times 0.55$ $\mathrm{nm}$ ) windows that connect the hemicavities of the MWW lamella could limit the access of benzaldehyde $(0.59 \times 0.49 \times 0.20 \mathrm{~nm})$ and pentaerythritol $(0.54 \times 0.53 \times 0.53 \mathrm{~nm})$ molecules to reach the active sites located within micropores. Indeed, the bulky product dibenzylidenepentaerythritol $(1.41 \times 8.62 \times 4.50 \mathrm{~nm})$ indicates that the reaction may occur at the sites located on the surface of MWW lamellae. The CR-MCM-22 allows to achieve a conversion of $29.7 \%$ within $2 \mathrm{~h}$, which is superior compared to the very low conversion achieved for conventional ZSM-5 (1\%) under similar reaction conditions. ${ }^{42}$ It was indeed previous reported that MCM-22 zeolites with Si/Al ratios $10-30$ possesses $50-70 \%$ of the active sites located in the 12-ring hemicavities $(0.71 \mathrm{~nm})$ on the MWW surface, whereas $20-30 \%$ of the active sites are located in the 10-ring sinusoidal channels. ${ }^{43}$ We can thus assume that the catalytic active sites for the development of the bulky acetal are majorly those located at the external surface of the MWW lamellae.

The pillared CR-MCM-36 sample achieves a higher conversion (49.4\%), which can be attributed to the improved diffusion and accessibility of reactants and products through the interlamellar mesopores created after pillaring. The pillars maintains the MWW lamellae separated and hence more 12-ring hemicavities are exposed on the individual MWW lamellae. Moreover, the hydrophobic nature of the catalyst increases because the introduction of silica pillars, which can further positively impact conversion for the reaction. Indeed, early studies with reaction of benzaldehyde with different aliphatic glycols using ordered mesoporous Al-MCM-41 materials with different Si/AI ratios $(108,81$, 57 and 36 ) indicates that the conversion is directly proportional to the hydrophobicity of the catalysts. ${ }^{41}$

Table 3. Acetalization of benzaldehyde with pentaerythritol over acidic CR-MCM-22, CR-MCM-36, CR-MCM-22[49] and CR-MCM-22[49] catalysts.

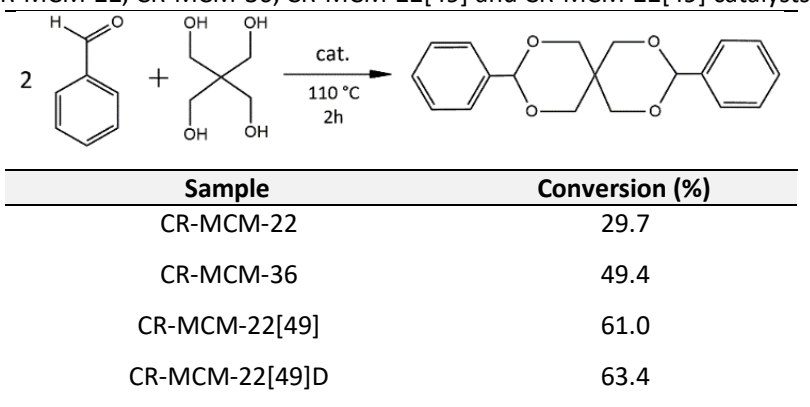

Conditions: Benzaldehyde $(5 \mathrm{mmol})$, pentaerythritol $(2.5 \mathrm{mmol})$, toluene $(2 \mathrm{~mL}), 10 \mathrm{mg}$ of catalyst, $110^{\circ} \mathrm{C}, 2 \mathrm{~h}$. 
The CR-MCM-22[49] allows to achieve a conversion which is twice that of CR-MCM-22 and is attributed to the stronger acidity of the catalyst, as shown in Table S2. Specifically, NMR results shows the increasing of framework aluminum in T-sites in 12-ring hemicavities located on the external surface of the zeolite, which are easily available for the reaction.

The desilicated CR-MCM-22[49]D leads to the highest conversion (63.4\%). This result indicates that the formation of intracrystalline mesoporosity compensates the decreasing of BAS.

In summary, the leaching of silica from rice husk ash is not a necessary condition to obtain MCM-22 with high crystallinity. Therefore, an environmentally benign synthesis (without the use of $\mathrm{HCl}$ as strong acid, high temperature and large water volume for neutralizing the acidic $\mathrm{pH}$ ) was disclosed through using calcined rice husk directly as silica source. We have demonstrated that silica extracted from rice husk ash plays a key role during the synthesis of MWW-type zeolites and the presence of cations has further an important impact when used as silica source. Therefore, a valid alternative route to obtain a more sustainable synthesis of hierarchical derivative MWW-type zeolites with controlled physico-chemical and morphological nature was stablished. Moreover, it was possible to obtain both accessibility level and associated acidity through pillaring and desilication procedures. The MWW-type materials demonstrate potential use for acetalization reactions, especially desilicated MWW-type zeolites that exhibited conversion at $63.4 \%$ after $2 \mathrm{~h}$ of reaction.

\section{Supporting Information}

$\mathrm{N}_{2}$ adsorption isotherms of CR and CLR silica sources, IR spectra of CR and CLR-MCM-22P precursors, weight losses values of precursors, $\mathrm{N}_{2}$ adsorption isotherms of CLR-MCM-22, crystallographic sites of MWW structure and their percentages, XRD of samples with different Si/AI ratio, number of BAS and LAS of the obtained materials.

\section{AUTHOR INFORMATION}

* Anderson Joel Schwanke: anderson-js@live.com

\section{Author Contributions}

The manuscript was written through contributions of all authors.

\section{ACKNOWLEDGMENTS}

Anderson Joel Schwanke thanks the CAPES Foundation (código 001), PPGQ-UFRGS and INOMAT (project number: 88887.136344/2017-00 - 465452/2014-0). Alexander Sachse acknowledges financial support from the European Union (ERDF) and "Région Nouvelle Aquitaine".

\section{REFERENCES}

1. Li, C.; Moliner, M.; Corma, A., Building Zeolites from Precrystallized Units: Nanoscale Architecture. Angew. Chem. Int. Ed. 2018, 57 (47), 15330-15353.

2. (a) Li, Y.; Cao, H.; Yu, J., Toward a New Era of Designed Synthesis of Nanoporous Zeolitic Materials. ACS Nano 2018, 12 (5), 4096-4104; (b) Dusselier, M.; Davis, M. E., Small-Pore Zeolites: Synthesis and Catalysis. Chem. Rev. 2018, 118 (11), 5265-5329.

3. (a) Kabalan, I.; Lebeau, B.; Nouali, H.; Toufaily, J.; Hamieh, T.; Koubaissy, B.; Bellat, J.-P.; Daou, T. J., New Generation of Zeolite Materials for Environmental Applications. The Journal of Physical Chemistry C 2016, 120 (5), 2688-2697; (b) Mintova, S.; Jaber, M.; Valtchev, V., Nanosized microporous crystals: emerging applications. Chem. Soc. Rev. 2015, 44 (20), 7207-7233; (c) Eroglu, N.; Emekci, M.; Athanassiou, C. G., Applications of natural zeolites on agriculture and food production. J. Sci. Food Agric. 2017, 97 (11), 3487-3499; (d) Derakhshankhah, H.; Hosseini, A.; Taghavi, F.; Jafari, S.; Lotfabadi, A.; Ejtehadi, M. R.; Shahbazi, S.; Fattahi, A.; Ghasemi, A.; Barzegari, E.; Evini, M.; Saboury, A. A.; Shahri, S. M. K.; Ghaemi, B.; Ng, E.-P.; Awala, H.; Omrani, F.; Nabipour, I.; Raoufi, M.; Dinarvand, R.; shahpasand, K.; Mintova, S.; Hajipour, M. J.; Mahmoudi, M., Molecular interaction of fibrinogen with zeolite nanoparticles. Scientific Reports 2019, 9 (1), 1558; (e) Davis, M. E., Zeolites from a Materials Chemistry Perspective. Chem. Mater. 2014, 26 (1), 239-245.

4. Jacobs, P. A.; Dusselier, M.; Sels, B. F., Will Zeolite-Based Catalysis be as Relevant in Future Biorefineries as in Crude Oil Refineries? Angew. Chem. Int. Ed. 2014, 53 (33), 8621-8626.

5. (a) Přech, J.; Pizarro, P.; Serrano, D. P.; Čejka, J., From 3D to 2D zeolite catalytic materials. Chem. Soc. Rev. 2018, 47 (22), 8263-8306; (b) Roth, W. J.; Gil, B.; Makowski, W.; Marszalek, B.; Eliasova, P., Layer like porous materials with hierarchical structure. Chem. Soc. Rev. 2016, 45 (12), 3400-3438.

6. Corma, A.; Díaz, U.; García, T.; Sastre, G.; Velty, A., Multifunctional Hybrid Organic-Inorganic Catalytic Materials with a Hierarchical System of Well-Defined Micro- and Mesopores. J. Am. Chem. Soc. 2010, 132 (42), 15011-15021.

7. (a) Roth, W. J.; Čejka, J.; Millini, R.; Montanari, E.; Gil, B.; Kubu, M., Swelling and Interlayer Chemistry of Layered MWW Zeolites MCM-22 and MCM-56 with High Al Content. Chem. Mater. 2015, 27 (13), 4620-4629; (b) Fung, A. S.; Lawton, S. L.; Roth, W. J. Synthetic layered MCM-56, its synthesis and use. 1994.

8. Corma, A.; Fornes, V.; Pergher, S. B. C.; Maesen, T. L. M.; Buglass, J. G., Delaminated zeolite precursors as selective acidic catalysts. Nature 1998, 396 (6709), 353-356. 
9. Gallego, E. M.; Paris, C.; Martínez, C.; Moliner, M.; Corma, A., Nanosized MCM-22 zeolite using simple non-surfactant organic growth modifiers: synthesis and catalytic applications. Chem. Commun. 2018, 54 (71), 9989-9992.

10. Roth, W. J.; Kresge, C. T.; Vartuli, J. C.; Leonowicz, M. E.; Fung, A. S.; McCullen, S. B., MCM-36: The first pillared molecular sieve with zeolite properties. In Stud. Surf. Sci. Catal., H.K. Beyer, H. G. K. I. K.; Nagy, J. B., Eds. Elsevier: 1995; Vol. Volume 94, pp 301-308.

11. (a) Ji, Y.-J.; Xu, H.; Wang, D.-R.; Xu, L.; Ji, P.; Wu, H.; Wu, P., Mesoporus MCM-22 Zeolites Prepared through Organic Amine-Assisted Reversible Structural Change and Protective Desilication for Catalysis of Bulky Molecules. ACS Catalysis 2013, 3 (8), 1892-1901; (b) Gao, N.; Xie, S.; Liu, S.; Xin, W.; Gao, Y.; Li, X.; Wei, H.; Liu, H.; Xu, L., Development of hierarchical MCM-49 zeolite with intracrystalline mesopores and improved catalytic performance in liquid alkylation of benzene with ethylene. Microporous Mesoporous Mater. 2015, 212, 1-7.

12. (a) Maheshwari, S.; Martínez, C.; Teresa Portilla, M.; Llopis, F. J.; Corma, A.; Tsapatsis, M., Influence of layer structure preservation on the catalytic properties of the pillared zeolite MCM-36. J. Catal. 2010, 272 (2), 298-308; (b) Corma, A.; Diaz, U.; Fornés, V.; Guil, J. M.; MartínezTriguero, J.; Creyghton, E. J., Characterization and Catalytic Activity of MCM-22 and MCM-56 Compared with ITQ-2. J. Catal. 2000, 191 (1), 218224; (c) Corma, A.; Corell, C.; Pérez-Pariente, J.; Guil, J. M.; Guil-López, R.; Nicolopoulos, S.; Calbet, J. G.; Vallet-Regi, M., Adsorption and catalytic properties of MCM-22: The influence of zeolite structure. Zeolites 1996, 16 (1), 7-14; (d) Aguilar, J.; Pergher, S. B. C.; Detoni, C.; Corma, A.; Melo, F. V.; Sastre, E., Alkylation of biphenyl with propylene using MCM-22 and ITQ-2 zeolites. Catal. Today 2008, 133-135, 667-672; (e) Carriço, C. S.; Cruz, F. T.; dos Santos, M. B.; Oliveira, D. S.; Pastore, H. O.; Andrade, H. M. C.; Mascarenhas, A. J. S., MWW-type catalysts for gas phase glycerol dehydration to acrolein. J. Catal. 2016, 334, 34-41.

13. Tanabe, K.; Hölderich, W. F., Industrial application of solid acid-base catalysts. Appl. Catal. A: 1999, 181 (2), 399-434.

14. Roth, W. J.; Nachtigall, P.; Morris, R. E.; Čejka, J., Two-Dimensional Zeolites: Current Status and Perspectives. Chem. Rev. 2014, 114 (9), 4807-4837.

15. Ng, E.-P.; Zou, X.; Mintova, S., Chapter 12 - Environmental Synthesis Concerns of Zeolites A2 - Suib, Steven L. In New and Future Developments in Catalysis, Elsevier: Amsterdam, 2013; pp 289-310.

16. Li, X.-Y.; Jiang, Y.; Liu, X.-Q.; Shi, L.-Y.; Zhang, D.-Y.; Sun, L.-B., Direct Synthesis of Zeolites from a Natural Clay, Attapulgite. ACS Sus. Chem. Eng. 2017, 5 (7), 6124-6130.

17. Schwanke, A. J.; Balzer, R.; Pergher, S., Microporous and Mesoporous Materials from Natural and Inexpensive Sources. In Handbook of Ecomaterials, Martínez, L. M. T.; Kharissova, O. V.; Kharisov, B. I., Eds. Springer International Publishing: Cham, 2017; pp 1-22.

18. FAO Rice Market Monitor, April 2018, Volume XXI - Issue No. 1.

19. Pode, R., Potential applications of rice husk ash waste from rice husk biomass power plant. Renew. Sus. Energy Rev. 2016, 53, 1468-1485.

20. Shen, Y., Rice husk silica derived nanomaterials for sustainable applications. Renew. Sus. Energy Rev. 2017, 80, 453-466.

21. (a) Xing, E.; Shi, Y.; Xie, W.; Zhang, F.; Mu, X.; Shu, X., Perspectives on the multi-functions of aniline: Cases from the temperature-controlled phase transfer hydrothermal synthesis of MWW zeolites. Microporous
Mesoporous Mater. 2017, 254, 201-210; (b) Chu, W.; Li, X.; Liu, S.; Zhu, X.; Xie, S.; Chen, F.; Wang, Y.; Xin, W.; Xu, L., Direct synthesis of threedimensional MWW zeolite with cyclohexylamine as an organic structuredirecting agent. J. Mater. Chem. A 2018.

22. Schwanke, A. J.; Díaz, U.; Corma, A.; Pergher, S., Recyclable swelling solutions for friendly preparation of pillared MWW-type zeolites. Microporous Mesoporous Mater. 2017, 253, 91-95.

23. Corma, A.; Corell, C.; Pérez-Pariente, J., Synthesis and characterization of the MCM-22 zeolite. Zeolites 1995, 15 (1), 2-8.

24. Maheshwari, S.; Jordan, E.; Kumar, S.; Bates, F. S.; Penn, R. L.; Shantz, D. F.; Tsapatsis, M., Layer Structure Preservation during Swelling, Pillaring, and Exfoliation of a Zeolite Precursor. J. Am. Chem. Soc. 2008, 130 (4), 1507-1516.

25. Brunauer, S.; Emmett, P. H.; Teller, E., Adsorption of Gases in Multimolecular Layers. J. Am. Chem. Soc. 1938, 60 (2), 309-319.

26. Lippens, B. C.; de Boer, J. H., Studies on pore systems in catalysts: V. The t method. J. Catal. 1965, 4 (3), 319-323.

27. Guisnet, M.; Ayrault, P.; Datka, J., Acid Properties of Dealuminated Mordenites Studied by IR Spectroscopy. 2. Concentration, Acid Strength and Heterogeneity of OH Groups. J. Pol. Chem. 1997, 71.

28. M. Thommes; K. Kaneko; A.V. Neimark; J.P. Olivier; F. RodriguezReinoso; J. Rouquerol; Sing, K. S. W., Physisorption of gases, with special reference to the evaluation of surface area and pore size distribution (IUPAC Technical Report). Pure Appl. Chem. 2015, 87 ((9-10)), 18.

29. Yalçin, N.; Sevinç, V., Studies on silica obtained from rice husk. Ceram. Int. 2001, 27 (2), 219-224.

30. Roth, W. J.; Dorset, D. L., Expanded view of zeolite structures and their variability based on layered nature of 3-D frameworks. Microporous Mesoporous Mater. 2011, 142 (1), 32-36.

31. Roth, W. J.; Cejka, J., Two-dimensional zeolites: dream or reality? Catal. Sci. Techn. 2011, 1 (1), 43-53.

32. Ma, D.; Deng, F.; Fu, R.; Han, X.; Bao, X., MAS NMR Studies on the Dealumination of Zeolite MCM-22. J. Phys. Chem. B 2001, 105 (9), 17701779.

33. Lawton, S. L.; Fung, A. S.; Kennedy, G. J.; Alemany, L. B.; Chang, C. D.; Hatzikos, G. H.; Lissy, D. N.; Rubin, M. K.; Timken, H.-K. C.; Steuernagel, S.; Woessner, D. E., Zeolite MCM-49: A Three-Dimensional MCM-22 Analogue Synthesized by in Situ Crystallization. J. Phys. Chem. 1996, 100 (9), 3788-3798.

34. Vuono, D.; Pasqua, L.; Testa, F.; Aiello, R.; Fonseca, A.; Korányi, T. I.; Nagy, J. B., Influence of $\mathrm{NaOH}$ and $\mathrm{KOH}$ on the synthesis of MCM-22 and MCM-49 zeolites. Microporous Mesoporous Mater. 2006, 97 (1), 78-87.

35. Hunger, M.; Ernst, S.; Weitkamp, J., Multinuclear solid-state n.m.r. investigation of zeolite MCM-22. Zeolites 1995, 15 (3), 188-192.

36. Schwieger, W.; Machoke, A. G.; Weissenberger, T.; Inayat, A.; Selvam, T.; Klumpp, M.; Inayat, A., Hierarchy concepts: classification and preparation strategies for zeolite containing materials with hierarchical porosity. Chem. Soc. Rev. 2016, 45 (12), 3353-3376. 
37. Sachse, A.; Grau-Atienza, A.; Jardim, E. O.; Linares, N.; Thommes, M.; García-Martínez, J., Development of Intracrystalline Mesoporosity in Zeolites through Surfactant-Templating. Cryst. Growth Des. 2017, 17 (8), 4289-4305.

38. Hufendiek, A.; Lingier, S.; Du Prez, F. E., Thermoplastic polyacetals: chemistry from the past for a sustainable future? Polym. Chem. 2019, 10 (1), 9-33.

39. Surburg, H.; Panten, J., Individual Fragrance and Flavor Materials Preparation, Properties and Uses. In Common Fragrance and Flavor Materials, 5th ed.; Wiley: Weinheim, 2006.

40. Wei, R.; Yang, H.; Scott, J. A.; Aguey-Zinsou, K.-F.; Zhang, D., Synthesis of 2D MFI zeolites in the form of self-interlocked nanosheet stacks with tuneable structural and chemical properties for catalysis. Appl. Mat. Today 2018, 11, 22-33.
41. Ajaikumar, S.; Pandurangan, A., Reaction of benzaldehyde with various aliphatic glycols in the presence of hydrophobic Al-MCM-41: A convenient synthesis of cyclic acetals. J. Mol. Catal. A: Chem. 2008, 290 (1), 35-43.

42. (a) Shetti, V. N.; Kim, J.; Srivastava, R.; Choi, M.; Ryoo, R., Assessment of the mesopore wall catalytic activities of MFI zeolite with mesoporous/microporous hierarchical structures. J. Catal. 2008, 254 (2), 296-303; (b) Sachse, A.; Wuttke, C.; Lissner, E.; Oberson de Souza, M., Ordered Mesoporous ZSM-5 Employing an Imidazolium-Based Ionic Liquid. Chem. - Eur. J. 2014, 20 (46), 14996-14999.

43. Meloni, D.; Laforge, S.; Martin, D.; Guisnet, M.; Rombi, E.; Solinas, V., Acidic and catalytic properties of H-MCM-22 zeolites: 1 . Characterization of the acidity by pyridine adsorption. Appl. Catal. A., 2001, 215 (1-2), 5566. 


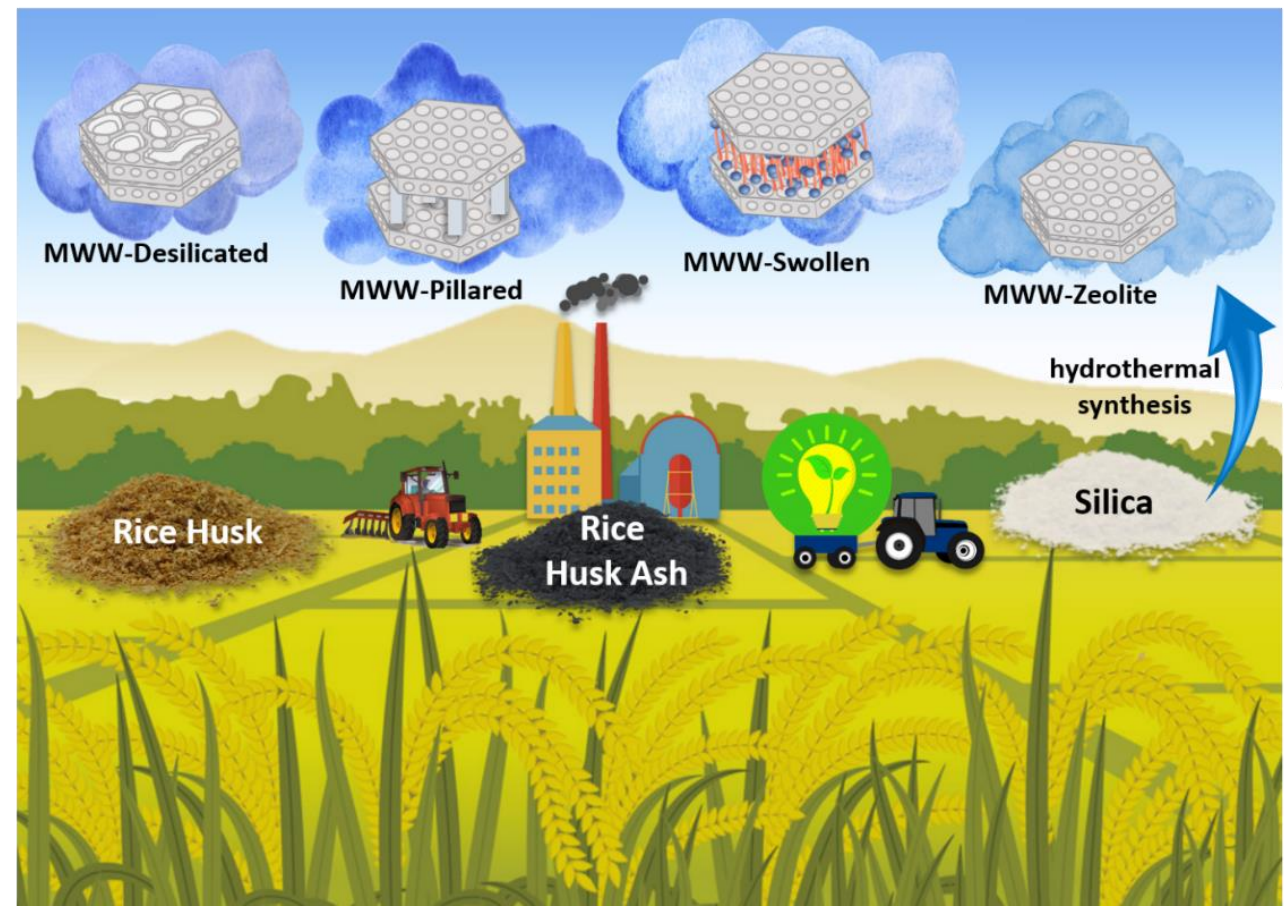

Synthesis of MWW zeolites with hierarchical pore architectures was realized using silica extracted from an agro-industrial residue, rice husk ash 